\title{
Sarocladium and Lecanicillium Associated with Maize Seeds and Their Potential to Form Selected Secondary Metabolites
}

\author{
Lidia Błaszczyk $^{1, *(D)}$, Agnieszka Waśkiewicz ${ }^{2}$, Karolina Gromadzka ${ }^{2}$, Katarzyna Mikołajczak ${ }^{1} @$ and \\ Jerzy Chełkowski ${ }^{1}$ \\ 1 Institute of Plant Genetics, Polish Academy of Sciences, Strzeszyńska 34, 60-479 Poznań, Poland; \\ kmiko@igr.poznan.pl (K.M.); jche@igr.poznan.pl (J.C.) \\ 2 Department of Chemistry, Poznan University of Life Sciences, Wojska Polskiego 75, 60-625 Poznań, Poland; \\ agnieszka.waskiewicz@up.poznan.pl (A.W.); karolina.gromadzka@up.poznan.pl (K.G.) \\ * Correspondence: lbla@igr.poznan.pl; Tel.: +48-61-65-50-272
}

check for

updates

Citation: Błaszczyk, L.; Waśkiewicz, A.; Gromadzka, K.; Mikołajczak, K.; Chełkowski, J. Sarocladium and Lecanicillium Associated with Maize Seeds and Their Potential to Form Selected Secondary Metabolites. Biomolecules 2021, 11, 98. https:// doi.org/10.3390/biom11010098

Received: 8 December 2020 Accepted: 11 January 2021 Published: 13 January 2021

Publisher's Note: MDPI stays neutral with regard to jurisdictional clai$\mathrm{ms}$ in published maps and institutional affiliations.

Copyright: (C) 2021 by the authors. Licensee MDPI, Basel, Switzerland. This article is an open access article distributed under the terms and conditions of the Creative Commons Attribution (CC BY) license (https:// creativecommons.org/licenses/by/ $4.0 /)$.

\begin{abstract}
The occurrence and diversity of Lecanicillium and Sarocladium in maize seeds and their role in this cereal are poorly understood. Therefore, the present study aimed to investigate Sarocladium and Lecanicillium communities found in endosphere of maize seeds collected from fields in Poland and their potential to form selected bioactive substances. The sequencing of the internally transcribed spacer regions 1 (ITS 1) and 2 (ITS2) and the large-subunit (LSU, 28S) of the rRNA gene cluster resulted in the identification of 17 Sarocladium zeae strains, three Sarocladium strictum and five Lecanicillium lecanii isolates. The assay on solid substrate showed that $S$. zeae and S. strictum can synthesize bassianolide, vertilecanin A, vertilecanin A methyl ester, 2-decenedioic acid and 10-hydroxy-8decenoic acid. This is also the first study revealing the ability of these two species to produce beauvericin and enniatin B1, respectively. Moreover, for the first time in the present investigation, pyrrocidine A and/or B have been annotated as metabolites of S. strictum and L. lecanii. The production of toxic, insecticidal and antibacterial compounds in cultures of S. strictum, S. zeae and L. lecanii suggests the requirement to revise the approach to study the biological role of fungi inhabiting maize seeds.
\end{abstract}

Keywords: maize seed-associated fungi; Sarocladium zeae; Sarocladium strictum; Lecanicillium lecanii; mycotoxins; bioactive compounds

\section{Introduction}

The seeds of many agronomically important crops such as maize (Zea maize L.) are frequently colonized by fungal communities, both externally and internally. Recent studies on the composition and variation in the seed-associated fungal mycobiomes have shown Aspergillus, Alternaria, Cladosporium, Curvularia, Fusarium, Mucor, Penicillium, Sarocladium, and Trichoderma to be the most prevalent fungal taxa in Ascomycota [1-3]. In Basidiomycota, Wallemia was the main genus observed to be associated with crop seeds [3]. Aspergillus, Fusarium, Wallemia, Sarocladium, and Penicillium were also reported as the predominant genera occurring in various maize kernel storage conditions [3]. At the species level, Cladosporium sphaerospermum, Penicillium aurantiogriseum, and Trichoderma gamsii were exclusively isolated from the internal tissue of maize seeds [2]. Aspergillus flavus, Aspergillus penicillioides, Aspergillus niger, Cladosporium cladosporioides, Fusarium andiyazi, Fusarium graminearum, Fusarium incarnatum-equiseti, Fusarium nygamai, Trichoderma longibrachiatum, Trichoderma harzianum, Penicillium digitatum, Mucor fragilis, and Wallemia sebi were isolated only from the surface of seeds [1-3]. However, Alternaria alternata, Fusarium verticillioides, Fusarium proliferatum, Penicillium oxalicum, Penicillium polonicum, and Sarocladium zeae were isolated from both the external surface and internal tissues [1-3]. The occurrence of $F$. verticillioides and $S$. zeae in maize seeds has also been reported in our previous study [4]. 
Moreover, our study documented the presence of Fusarium subglutinans, Trichoderma atroviride, and Lecanicillium lecanii [4]. These species were identified on average from 1 to $35 \%$ in maize ear samples with Fusarium maize ear rot (MER) symptoms.

Most of the maize seed-associated fungi are classified as commensals with yet unknown functions in plants or as pathogens that include toxigenic Fusarium and Aspergillus species [1-3]. The less common ones are those shown to have beneficial effects on plants, such as Trichoderma, which is a well-known important Microbial Biological Control Agent (MBCA) that can protect maize plants and enhance their vegetative growth [5]. Several studies have reported a seed-borne protective endophyte of maize, namely Sarocladium zeae, as Acremonium zeae [6-8], which produces dihydroresorcylide and pyrrocidine metabolites that are antagonistic to $A$. flavus and F. verticillioides $[6,7]$ as well as hydrolytic enzymes such as amylases, proteases, cellulases, and lipases [1]. However, knowledge about the role of endophytic Sarocladium species, including S. zeae or Sarocladium strictum, in maize is still scarce. There is accumulating evidence that entomopathogenic, nematophagous Lecanicillium spp. may demonstrate activity against fungal plant pathogens $[9,10]$. However, to the best of our knowledge, no studies have investigated how the seed-associated Lecanicillium species interact with maize plants. The occurrence and diversity of both Lecanicillium and Sarocladium in maize seeds and their role in maize plants are still poorly understood. In addition, the potential of these maize seed-borne fungi to produce toxic and/or insecticidal and antibacterial compounds has not yet been demonstrated. Therefore, to gain insights into their diversity, including their ability to produce secondary metabolites, the present study aimed to investigate Sarocladium and Lecanicillium communities found in maize ears collected from fields before harvest in Poland and their potential to form selected bioactive substances. This could open the way to understanding the functions of endogenous Sarocladium and Lecanicillium species and indicates a strategy for selecting potential candidates for the biological protection of maize crops.

\section{Materials and Methods}

\subsection{Fungal Collection}

The 17 S. zeae strains, three S. strictum strains, and five L. lecanii strains investigated in the present study are listed in Table 1 . Seven S. zeae strains, one S. strictum strain and five $L$. lecanii strains sourced from maize ears sampled in October 2015 from the Greater Poland Region (maize field location: $50^{\circ} 58^{\prime} \mathrm{N}, 16^{\circ} 55^{\prime} \mathrm{E}$ ) in Poland had been previously isolated and identified by Gromadzka et al. [4]. Ten S. zeae strains and two S. strictum strains were isolated from maize ears collected before harvest in October 2018 (56 samples) from the same maize field location ( $\left.50^{\circ} 58^{\prime} \mathrm{N}, 16^{\circ} 55^{\prime} \mathrm{E}\right)$ in the Greater Poland Region (Poland).

\subsection{Fungal Isolation and Identification}

The maize ear samples collected in 2018 were placed in separate paper bags, transported to the laboratory, and dried at room temperature. The maize ears were then hand-shelled, and the separated kernels from each ear were cut with a sterile scalpel and placed in duplicate on agar plates containing a low nutrient SNA medium [11]. A tip of hyphae from each off-white culture was transferred to both potato dextrose agar and synthetic SNA low nutrient agar, and multiple passages were performed to obtain a homogeneous culture. The isolates with cultural and morphological characteristics $[8,12]$ of Sarocladium and Lecanicillium were molecularly identified as described by Gromadzka et al. [4]. The results of species identification of all Lecanicillium strains isolated in 2015 were additionally verified on the basis of sequencing of the large-subunit (LSU, 28S) rDNA region. The results of species identification of all Sarocladium strains isolated in both 2015 and 2018 (Table 1) were additionally verified on the basis of sequencing of the large-subunit (LSU, 28S) rDNA region and a fragment of the actin gene (ACT1). The 1200-bp target region of rDNA LSU was amplified using the primers LROR [13] and LR6 [14] by PCR annealing at $52{ }^{\circ} \mathrm{C}$ and the 370 -bp fragment of the actin gene was amplified using primer pair ACT 512-F and ACT 783-R [15] by PCR annealing at $55^{\circ} \mathrm{C}$. Other conditions of PCR 
and sequencing were the same as those reported by Gromadzka et al. [4]. For identification, the sequences were matched against the nucleotide database using BLASTn (Basic Local Alignment Search Tool) from NCBI [16]. All the LSU and ITS rDNA sequences obtained here as well as reported by Gromadzka et al. [4] were deposited in the NCBI GenBank [16]. The accession numbers are provided in Table 1.

Table 1. The list of identified or re-identified in present study endophytic fungi isolated from maize ear samples collected in the Greater Poland Region.

\begin{tabular}{|c|c|c|c|c|}
\hline \multirow{2}{*}{ Species } & \multirow{2}{*}{ Isolate Code } & \multirow{2}{*}{ Sampling Year } & \multicolumn{2}{|c|}{ NCBI GenBank Accession No. } \\
\hline & & & ITS & LSU \\
\hline \multirow{5}{*}{$\begin{array}{l}\text { Lecanicillium } \\
\quad \text { lecanii }\end{array}$} & 207 & \multirow{5}{*}{2015} & MT372981 & MT373083 \\
\hline & 213 & & MT372982 & MT373084 \\
\hline & 224 & & MT375133 & МT375130 \\
\hline & 350 & & MT372983 & MT373085 \\
\hline & 345 & & MT372984 & MT373086 \\
\hline \multirow{3}{*}{$\begin{array}{l}\text { Sarocladium } \\
\text { strictum }\end{array}$} & 228 & 2015 & MT375132 & MT375131 \\
\hline & 626 & \multirow{2}{*}{2018} & MT372901 & MT374074 \\
\hline & 605_1 & & MT372902 & MT374075 \\
\hline \multirow{17}{*}{ Sarocladium zeae } & $21 \overline{5}$ & \multirow{7}{*}{2015} & MT372974 & МT373076 \\
\hline & 217 & & MT372976 & MT373078 \\
\hline & 220 & & MT372977 & МT373079 \\
\hline & 221 & & MT372978 & MT373080 \\
\hline & 226 & & MT372979 & МT373081 \\
\hline & $227 \mathrm{~A}$ & & MT372980 & MT373082 \\
\hline & 227B & & MT372975 & MT373077 \\
\hline & 601 & \multirow{10}{*}{2018} & MT372893 & MT374066 \\
\hline & 603 & & MT372894 & МТ374067 \\
\hline & 605 & & MT372895 & МТ374068 \\
\hline & 606 & & MT372896 & MT374069 \\
\hline & 613 & & MT372893 & MT374066 \\
\hline & 614 & & MT372899 & MT374072 \\
\hline & 636 & & MT372897 & МТ374070 \\
\hline & 651 & & MT372898 & MT374071 \\
\hline & 652 & & MT372899 & MT374072 \\
\hline & 658 & & MT372900 & МТ374073 \\
\hline
\end{tabular}

\subsection{Chemicals and Reagents}

Mycotoxin standards (enniatins (Enns) and beauvericin (BEA)) and all chemicals were obtained from Sigma-Aldrich (Steinheim, Germany). HPLC-grade water from our own Millipore water purification system was used for analyses.

\subsection{Secondary Metabolite Production}

Sarocladium and Lecanicillium isolates studied for the production of secondary metabolites were grown on a rice solid medium. In a $300 \mathrm{~mL}$ Erlenmeyer flask, $50 \mathrm{~g}$ of commercially available rice kernels and $15 \mathrm{~mL}$ of distilled water were added, and the flask was left overnight prior to autoclaving at $121{ }^{\circ} \mathrm{C}$ for $30 \mathrm{~min}$. The cooled flasks were inoculated with four disks ( $4 \mathrm{~mm}$ diameter) cut from the advancing edge of a 14-day PDA culture of the fungal isolates. Three replicates were prepared for each fungal isolate. A non-inoculated rice solid medium was used as a negative control. The cultures were incubated at $24 \pm 2{ }^{\circ} \mathrm{C}$ for 21 days under semi-static conditions (the flasks were manually shaken daily to avoid lumping and anaerobic conditions). After incubation the samples from solid substrate cultures were dried under air and room temperature conditions and ground to fine powder in the grinder. 


\subsection{Sample Extraction and HPLC Analysis of Enns and BEA}

Ground material was extracted using $2.5 \mathrm{~mL}$ of acetonitrile-methanol-water solution $(16: 3: 1 \mathrm{v} / \mathrm{v} / \mathrm{v})$ per gram of sample and then homogenized. The extracts were purified on Florisil columns, and mycotoxins were then estimated using a chromatographic system as described by Jestoi [17].

HPLC analyses of Enns and BEA were performed using a Waters 2695 system equipped with a Waters 2996 Array Detector. The reversed phase column was a C-18 Nova Pak column $(3.9 \times 150 \mathrm{~mm})$. Samples were eluted with acetonitrile-water $(70: 30, v / v)$ at a constant flow rate of $1 \mathrm{~mL} \mathrm{~min}^{-1}$ for $45 \mathrm{~min}$. Mycotoxins were detected at $205 \mathrm{~nm}$. Enns and BEA were quantified by comparing peak areas of the analyzed samples with the calibration curve of peak areas obtained with authentic mycotoxin standards.

\subsection{Qualitative Analysis of Selected Metabolites Formed by L. lecanii, S. zeae and S. strictum Isolates Using UPLC/TQD}

In order to acquire mass data product-ion spectra of selected metabolites [6,18-20], the extracts were analyzed using the Aquity UPLC chromatograph (Waters, Manchester, MA, USA), coupled with an electrospray ionization triple quadrupole mass spectrometer (TQD) (Waters, Manchester, MA, USA). Separation was achieved on a BEH C18 column $\left(100 \mathrm{~mm} \times 2.1 \mathrm{~mm}\right.$ i.d., $1.7 \mu \mathrm{m}$ particle size) (Waters, Manchester, MA, USA) held at $30^{\circ} \mathrm{C}$ with the injection volume $3 \mu \mathrm{L}$ and flow rate $0.3 \mathrm{~mL} / \mathrm{min}$. Elution proceeded by means of a linear gradient with solvents $\mathrm{A}(5 \mathrm{mM}$ ammonium format) and $\mathrm{B}$ (acetonitrile) as follows: $0-1 \mathrm{~min}, 20 \% \mathrm{~B} ; 1-30 \mathrm{~min}, 80 \% \mathrm{~B} ; 30-45 \mathrm{~min}, 85 \% \mathrm{~B} ; 45-47 \mathrm{~min}, 20 \% \mathrm{~B}$. The mass spectrometer was operated in the full-scan mode in the mass range $\mathrm{m} / \mathrm{z}$ 150-950.

\section{Results and Discussion}

\subsection{Isolation and Identification or Re-Identification of Sarocladium and Lecanicillium Species} Associated with Maize Seeds

Of 26 maize ear samples collected in October 2018 in the Greater Poland Region, six samples $(23 \%)$ were found to be the source of Sarocladium spp. Twelve Sarocladium isolates were grown. The morphological and molecular analysis, based on the NCBI GenBank search [16] for sequences homologous over $99-100 \%$ similarity to the obtained $A C T 1$ sequences and LSU and ITS rDNA sequences, resulted in the identification of two species, namely S. zeae (10 isolates) and S. strictum (two isolates). However, no Lecanicillium spp. were isolated from the kernels of these 26 samples. In contrast, in $47 \%$ of maize ear samples collected in 2015 from the Greater Poland Region, both Sarocladium spp. and Lecanicillium spp. were isolated [4]. The 13 previously obtained isolates were molecularly re-identified as S. zeae (seven isolates), S. strictum (one isolate), and L. lecanii (five isolates). Thus, in both 2015 [4] and 2018, S. zeae was the most frequently isolated species of the genus Sarocladium from maize kernels collected in the Greater Poland Region. The occurrence of $S$. zeae in maize kernels has also been reported in other studies. Initially, Reddy and Holbert [21] described A. zeae (S. zeae) as the seed-borne causal agent of "black-bundle disease" of maize. Recently, Wicklow et al. [6] and Wicklow and Polling [7] identified $S$. $z e a e$ as the beneficial endophyte in maize seeds sampled from USA. Abe et al. [1] evaluated 46 fungal isolates obtained from maize grains with rot symptoms collected from Brazil and found only one S. zeae isolate. This isolate was found to produce extracellular hydrolases, namely amylases, cellulases, proteases, and lipases. Sarocladium zeae has also been reported as the component of the mycobiota associated with stored maize kernels in China $[2,3]$. Xing et al. [2] showed that the occurrence of $S$. zeae varies depending on storage time; in samples stored from 6 months to 5 years, S. zeae was found only on the seed surface, while in older samples ( $>9$ years), $S$. zeae was isolated from the internal parts of maize seeds. Wang et al. [3] assessed changes occurring in the mycobiome of maize seeds during 12 months of storage and the complex of essential oil treatment using a nonculture-based approach. They demonstrated that $S$. zeae was the predominant species from the genus Sarocladium, while its relative abundance varied with storage time or treatment (and was 
lower in the late stages of storage and after essential oil treatment than during the early stages and in control samples).

Sarocladium strictum was the second species of the genus Sarocladium found in maize seeds in the present study. This species was represented by only three isolates, namely one (228) from the 2015 season and the remaining two (626 and 605_1) from the 2018 season. In 1995, Tagne examined the occurrence of fungi associated with maize from Cameroon and identified S. strictum (as A. strictum) as one of the most frequently occurring species in maize seeds. Further research on the interaction between maize and $S$. strictum (as A. strictum) isolates from Cameroon led to the detection of the pathogenic nature of this species [22]. Sarocladium strictum, as A. strictum, was also found to cause disease of strawberry plants [23]. Recent studies on the fungal communities associated with the endosphere of maize plants from India revealed the presence of $S$. strictum in maize nodes [24]. However, the metabarcoding analysis of microbiota in harvested maize samples from Brittany and France showed the occurrence of S. strictum in maize stalks [25]. Additionally, Cobo-Díaz et al. [25] showed negative correlations of operational taxonomic units (OTUs) assigned to S. strictum to OTUs assigned to F. oxysporum, thus suggesting the antagonistic potential of these species and the need for its further validation by using culture-dependent approaches.

Studies complementary to previous research of Gromadzka et al. [4] involving sequence analysis of the LSU rDNA region confirmed five Lecanicillium isolates as L. lecanii (Zimm.) Zare and Gams (homotypic synonym: Akanthomyces lecanii (Zimm.) Spatafora, Kepler and B. Shrestha and Verticillium lecanii (Zimm.) Viegas, Zare and Games [26], Kepler et al. [27]; heterotypic synonym Cordyceps confragosa (Mains) [28]). Lecanicillium spp. are well-known entomopathogenic and nematophagous fungi with antagonistic activity against several plant pathogens $[9,10,12,29]$. They have also been described as beneficial plant endophytes [30]. Lecanicillium lecanii has been reported as a natural endophyte in Ammophila arenaria [31], Dactylis glomerata [32], Deschampsia flexuosa [33], Elymus farctus [31], Laretia acaulis [34], Pinus sylvestris [35], and Taxus baccata [36] and the species whose colonization can be induced (triggered) by artificial inoculation. The latter aspect is mainly related to crops such as Cucurbita maxima [37], Gossypium hirsutum [38], Solanum lycopersicum [37], Phaseolus vulgaris [37,39], Pistacia vera [10], Triticum aestivum [37], Vitis vinifera [40], and Zea mays [37]. To the best of our knowledge, other than the recent study of Gromadzka et al. [4], there are no data on the natural endophytism of Lecanicillium lecanii in maize.

\subsection{Production of Mycotoxins and Other Compounds by the Investigated Sarocladium and Lecanicilium Isolates}

The isolates of Sarocladium and Lecanicillium species were assessed for their ability to biosynthesize mycotoxins and other metabolites. Primarily, the most common toxins occurring in Poland were considered: zearalenone; deoxynivalenol; nivalenol; moniliformin; fumonisins; BEA; and Enns A, A1, B, and B1 [41]. The assay on solid substrate (rice) showed that only Sarocladium spp. can synthesize two of these mycotoxins, namely BEA and Enn B1. The production of BEA was detected in cultures of all the three tested isolates belonging to $S$. zeae, namely 226, 227a, and 227b (Figure 1). The highest amount of toxin was $1028.39 \mathrm{ng} / \mathrm{g}$ for the isolate $227 \mathrm{~b}$ and the lowest amount was $549.10 \mathrm{ng} / \mathrm{g}$ for the isolate 227a. The toxin amount for the third isolate 226 was estimated at $807.68 \mathrm{ng} / \mathrm{g}$. It is interesting to note that all these isolates were collected in 2015, and the isolates 227a and $227 \mathrm{~b}$ were obtained from seeds of the same maize ears. As observed in the present study, the presence of BEA varied in cultures of S. zeae isolates. Thus, this characteristic appeared to be isolate-specific, and not species-specific. The presence of Enn B1 was noted in cultures of all isolates of $S$. strictum. The toxin content of these three isolates ranged from 16.63 to $62.40 \mathrm{mg} / \mathrm{g}$ (Figure 2). The present study is the first report on the production of BEA by $S$. zeae and Enn B1 by S. strictum. As S. strictum is considered to be a plant pathogen [22,23], the ability to produce Enn B1 in isolates from this species is not so controversial as that in the case of $S$. zeae, which is a known plant beneficial endophyte $[6,7]$. 


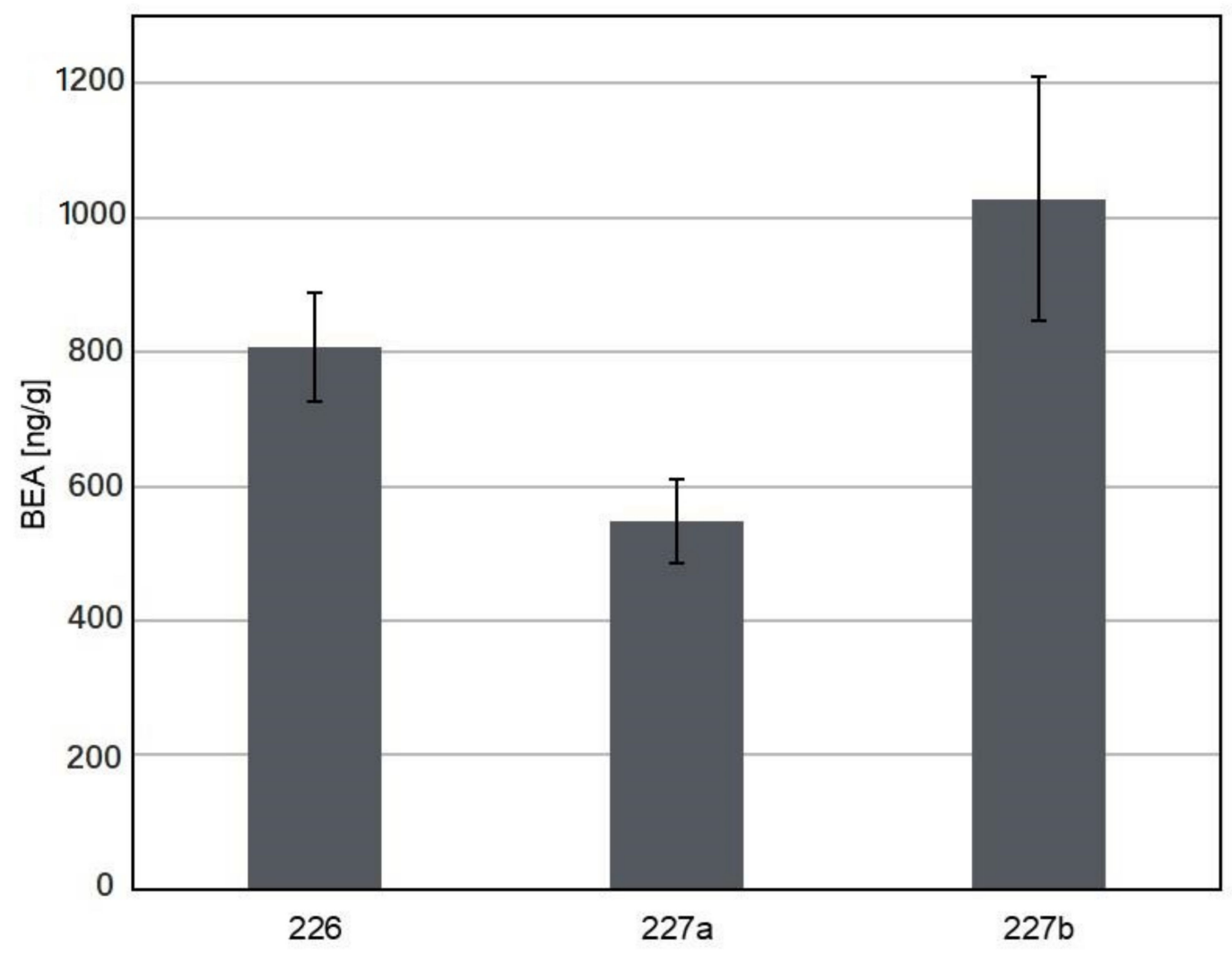

Figure 1. Bauvericin production by S. zeae 226, 227a, and 227b isolates.

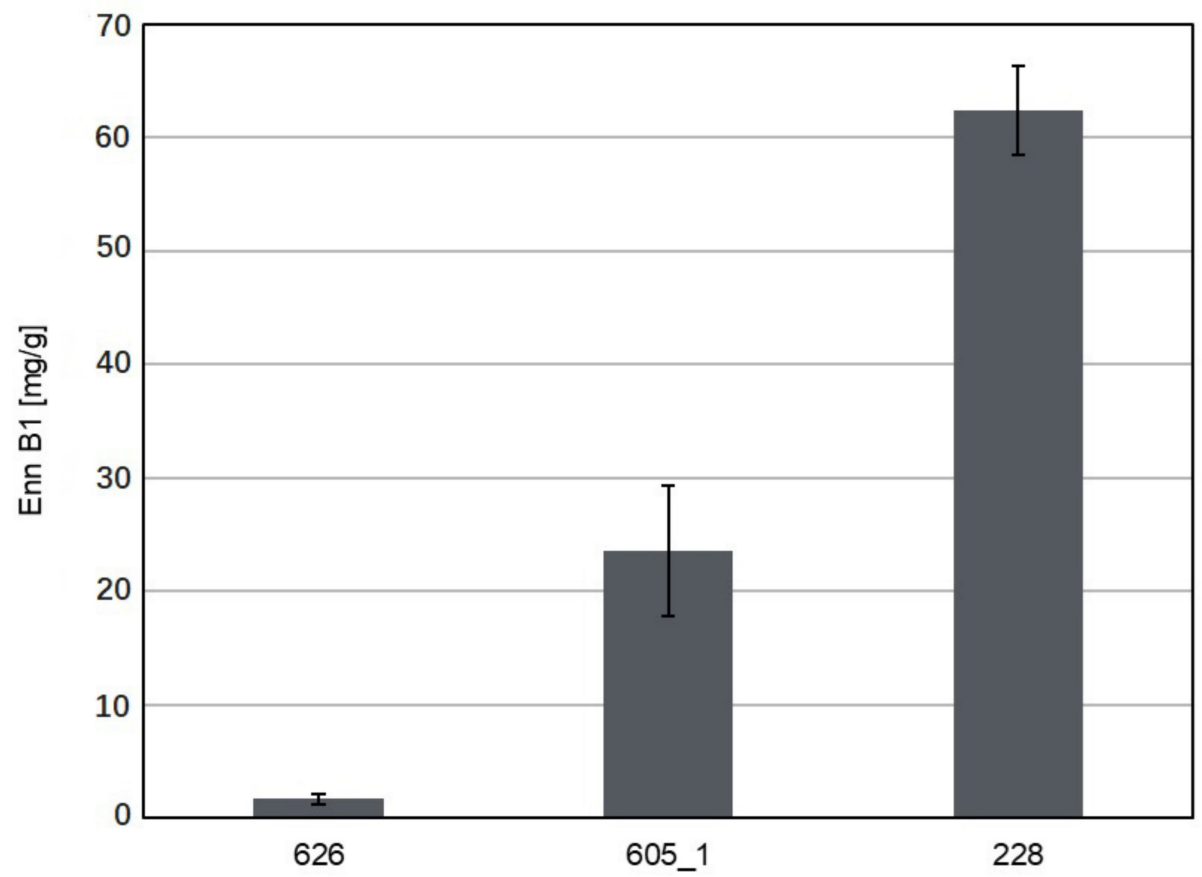

Figure 2. Enniatin B1 production by S. strictum 626, 605_1 and 228 isolates. 
Apart from BEA and Enn B1, a qualitative analysis showed that 20 Saracladium and five Lecanicillium isolates can synthesize other compounds, including those showing insecticidal and antimicrobial activity [6,18-20]. However, the profile of these metabolites was found to be different in the three investigated species (Table 2). Moreover, intraspecies variability was observed in the synthesis of phenopicolinic acid derivatives (vertilecanins), 2-decenedioic acid, 10-hydroxy-8-decenoic acid as well as pyrrocidine A and pyrrocidine B (Table 2). Vertilecanin A was present in all Sarocladium isolates, but was not synthesized by Lecanicillium spp. Vertilecanin B was not found in any of the tested cultures. Vertilecanin C was produced by one L. lecanii isolate 207 and two S. zeae isolates: 215 and 217. It is worth noting that although Lecanicillium isolates did not synthesize vertilecanin A, they produced its derivative vertilecanin A methyl ester. In addition, vertilecanin A methyl ester was also detected in solid substrate cultures of all S. strictum isolates and in 11 S. zeae isolates. The studied L. lecanii isolates also did not synthesize 10-hydroxy-8-decenoic acid, while this compound was produced by all S. strictum and eight $S$. zeae isolates. 2-decenedioic acid was synthesized by two Lecanicillium isolates, namely 207 and 213; seven S. zeae isolates; and three tested S. strictum isolates. Pyrrocidine A and B were identified in cultures of five of the 17 tested $S$. zeae isolates, namely those that were the only ones to produce BEA-226, 227A and 227B as well as in 601 and 614. Moreover, both of these compounds were identified in S. strictum 228 isolates, while pyrrocidine A alone was detected as the product of $S$. strictum strain $605-1$ and pyrrocidine B as the product of S. strictum 626. Pyrrocidine B was also synthesized by S. zeae 220, 603, 605, 606, 613 and 652 and L. lecanii 207, 213, with no production of pyrrocidine A. However, neither of these two metabolites were detected in the cultures of S. zeae 215, 217, 221, 651, 658 and L. lecanii 340, 345 isolates.

As shown in the Table 2, the only metabolite formed in the cultures of all the tested Lecanicillium and Sarocladium isolates was bassianolide. This active insecticidal cyclodepsipepside was previously reported as products of L. lecanii [18]. The finding that all $L$. lecanii isolates tested here could produce bassianolide was consistent with the study of Kanaoka et al. [18]. However, for the first time in the present study, these compounds were annotated as metabolites of $S$. strictum and S. zeae, which may suggest the insecticidal properties of S. zeae and S. strictum species. This could also be supported by the currently observed ability of S. zeae and S. strictum to produce another metabolite with confirmed insecticidal and antibacterial activity, namely vertilecanin A. Verticilian A was also first described as a metabolite of L. lecanii ([19], as Verticillium lecanii). Interestingly, none of the currently tested L. lecanii isolates synthesized vertilecanin A. Soman et al. [19] reported that solid substrate (rice) cultures of L. lecanii (as Verticillium lecanii) produced four other phenopicolinic acid derivatives as well, namely vertilecanin A methyl ester, vertilecanin $B$, vertilecanin B methyl ester, vertilecanin $C$ as well as 10-hydroxy-8-decenoic acid and 2-decenedioic acid. Among them, only vertilecanin A methyl ester and vertilecanin $C$ were detected as metabolites of L. lecanii in the present study, wherein vertilecanin A methyl ester was detected in the culture of all the tested L. lecanii isolates and vertilecanin C was found only in L. lecanii isolate 207. Moreover, these (vertilecanin A methyl ester, vertilecanin C) as well as 10-hydroxy-8-decenoic acid were detected in the cultures of the tested here $S$. zeae. Whereas vertilecanin A methyl ester and 10-hydroxy-8-decenoic acid were noted as products of $S$. strictum. This is the first report that vertilecanin A methyl ester, vertilecanin $C$ and 10-hydroxy-8-decenoic acid are described as S. strictum and/or S. zeae metabolites. However, the insecticidal or antibiotic activity of these compounds has not been demonstrated so far, or even excluded by Soman et al. [19]. Whereas, antimicrobial activity was confirmed for pyrrocidines, mainly pyrrocidin A, which were first isolated from fermentation broth of an unidentified filamentous fungus LL-Cyan426 [20]. He at al. [20] demonstrated the potent antibiotic activity of pyrrocidine A against most Gram-positive bacteria, including the drug-resistant strains, and moderate activity against Streptococcus pneumonia as well as yeast Candida albicans. Pyrrocidine A and B were then detected in fermentation extracts of S. zeae (as A. zeae) strains isolated from maize kernels harvested in various locations in the USA and exhibiting antagonistic potential to kernel 
rotting and mycotoxin producing fungi Aspergillus flavus and Fusarium verticillioides [6]. As in the present study, also in the work of Wicklow et al. [6], the pyrrocidine profiles showed differences between the $S$. zeae isolates. Wicklow et al. [6] determined the presence of pyrrocidines in ethyl acetate extracts of maize kernel fermentations for 12 out of 13 tested cultures of S. zeae. The authors reported that Pyrrocidine A and B were detected in nine of the cultures, while pyrrocidine B alone was detected in three cultures. Subsequent studies by Wicklow et al. [42] confirmed the variation in the distribution of pyrrocidines in the populations of maize endophytes $S$. zeae and supported that the ability of these fungi to form pyrrocidine A and B appeared to be isolate-specific and not species-specific. These findings are consistent with the observations from the present study. Here, apart from S. zeae, pyrrocidines were also found in the rice solid cultures of S. strictum and L. lecanii isolates. Moreover, pyrrocidine A and B were detected in culture of S. strictum 226, pyrrocidine A alone was identified in the culture of S. strictum 605_1, and pyrrocidine B in the culture of S. strictum 626 as well as in the fermentation extracts for $3(207,213,224)$ cultures of L. lecanii.

It is noteworthy that pyrrocidines A and B were discovered to be the metabolites accounting for S. zeae antifungal activity against Aspergillus flavus and Fusarium verticillioides [6,43]. Moreover, Wicklow et al. [42] documented that Pyrrocidine A displayed in vitro activity against major stalk and ear rot pathogens of maize, including F. graminearum, Nigrospora oryzae, Stenocarpella (Diplodia) maydis, and Rhizoctonia zeae as well as seed-infecting colonists of the phylloplane Alternaria alternata, Cladosporium cladosporioides, and Curvularia lunata, which produces a damaging leaf spot disease and seed-rotting saprophyte Eupenicillium ochrosalmoneum. Following the suggestion of Wicklow et al. [6,42] that the ability of fungal endophytes to produce pyrrocidine A and B may be important for their interaction with competing microorganisms, it can be assumed that the capacity of maize seed-associated Sarocladium and Lecanicillium isolates to synthesize these and other antibiotics (bassianolide, vericillian A) observed in present study may also signal their antagonistic potential towards other fungi. It is worth noting that the sources of endophytic isolates tested here were maize ear samples, with (suppression of the Fusarium spp. populations) a lower infestation by the populations of Fusarium spp., which could be an expression of the antagonistic abilities of these isolates towards Fusarium species [4]. It also leads to the presumption that maize ear without Fusarium ear rot symptoms can be a source of valuable endophytic fungi with antagonistic potential. Moreover, the analysis of the ability of isolated endophytic fungi to form selected bioactive compounds in solid substrate cultures allowed to identify potential antagonists. This approach may therefore constitute the candidates' pre-selection strategy for biological control agents screening studies. 
Table 2. The profiles of selected metabolites formed by L. lecanii, S. zeae and S. strictum isolates grown on a rice solid medium.

\begin{tabular}{|c|c|c|c|c|c|c|c|c|c|c|c|}
\hline \multicolumn{2}{|c|}{ Compound } & \multirow{2}{*}{$\begin{array}{l}\text { 10-hydoksy-8- } \\
\text { decenoic } \\
\text { acid }\end{array}$} & \multirow{2}{*}{$\begin{array}{l}\text { 2-decenedioic } \\
\text { acid }\end{array}$} & \multirow{2}{*}{ Verttilecanin A } & \multirow{2}{*}{$\begin{array}{c}\text { Verttilecanin } \\
\text { A methy } \\
\text { ester }\end{array}$} & \multirow{2}{*}{ Verttilecanin C } & \multirow{2}{*}{ Pyrrocidine A } & \multirow{2}{*}{ Pyrrocidine B } & \multirow{2}{*}{ Enns B1 } & \multirow{2}{*}{ BEA } & \multirow{2}{*}{ Bassianolide } \\
\hline Species & Isolate Code & & & & & & & & & & \\
\hline \multirow{5}{*}{$\begin{array}{c}\text { L. } \\
\text { lecanii }\end{array}$} & 207 & -1 & $t^{2}$ & - & + & + & - & + & - & - & + \\
\hline & 213 & - & + & - & + & - & - & + & - & - & + \\
\hline & 224 & - & - & - & + & - & - & + & - & - & + \\
\hline & 350 & - & - & - & + & - & - & - & - & - & + \\
\hline & 345 & - & - & - & + & - & - & - & - & - & + \\
\hline \multirow{2}{*}{$\begin{array}{l}\text { S. stric- } \\
\text { tum }\end{array}$} & 228 & + & + & + & + & - & + & + & + & - & + \\
\hline & 605_1 & + & + & + & + & - & + & - & + & - & + \\
\hline \multirow{16}{*}{ S. zeae } & $21 \overline{5}$ & + & - & + & + & + & - & - & - & - & + \\
\hline & 217 & + & + & + & + & + & - & - & - & - & + \\
\hline & 220 & - & - & + & + & - & - & + & - & - & + \\
\hline & 221 & + & + & + & + & - & - & - & - & - & + \\
\hline & 226 & + & + & + & + & - & + & + & - & + & + \\
\hline & $227 \mathrm{~A}$ & + & + & + & + & - & + & + & - & + & + \\
\hline & $227 \mathrm{~B}$ & + & - & + & + & - & + & + & - & + & + \\
\hline & 601 & - & - & + & + & - & + & + & - & - & + \\
\hline & 605 & - & + & + & + & - & - & + & - & - & + \\
\hline & 606 & + & - & + & - & - & - & + & - & - & + \\
\hline & 613 & - & - & + & + & - & - & + & - & - & + \\
\hline & 614 & - & - & + & - & - & + & + & - & - & + \\
\hline & 636 & - & + & + & + & - & - & + & - & - & + \\
\hline & 651 & - & - & + & - & - & - & - & - & - & + \\
\hline & 652 & - & + & + & - & - & - & + & - & - & + \\
\hline & 658 & - & - & + & - & - & - & - & - & - & + \\
\hline
\end{tabular}




\section{Conclusions}

The present study reported the screening of 17 S. zeae isolates, three S. strictum isolates, and five L. lecanii isolates originating from the endosphere of maize seeds for the formation of selected metabolites in solid substrate cultures. BEA, bassianolide, vertilecanin A, vertilecanin A methyl ester, 2-decenedioic acid, 10-hydroxy-8-decenoic acid have not yet been reported to be produced by $S$. zeae. This is also the first study to reveal the ability of S. strictum to produce Enn B1, bassianolide, vertilecanin A, vertilecanin A methyl ester, 2-decenedioic acid, 10-hydroxy-8-decenoic acid and pyrrocidine A and B. It should be also noted that pyrrocidine $\mathrm{B}$ has never been detected in the rice solid cultures of $L$. lecanii isolates. The production of several bioactive substances, namely toxic and/or insecticidal and antibacterial compounds, in cultures of S. strictum, S. zeae and L. lecanii suggests that more comprehensive studies and revising the approach to investigate the biological role of fungi inhabiting maize seeds is needed.

Author Contributions: Conceptualization, L.B., K.G. and J.C.; fungi isolation and cultivation, J.C.; fungi identification, L.B. and K.M.; chemical analysis, A.W. and K.G.; writing-original draft preparation, L.B.; writing - review and editing, A.W., K.G., K.M., J.C.; visualization, L.B., K.G. All authors have read and agreed to the published version of the manuscript.

Funding: This research received no external funding.

Institutional Review Board Statement: Not applicable.

Informed Consent Statement: Not applicable.

Data Availability Statement: National Centre for Biotechnology Information, https:/ /www.ncbi. nlm.nih.gov/genbank/.

Conflicts of Interest: The authors declare no conflict of interest.

\section{References}

1. Abe, C.A.; Faria, C.B.; de Castro, F.F.; de Souza, S.R.; dos Santos, F.C.; da Silva, C.N.; Tessmann, D.J.; Barbosa-Tessmann, I.P. Fungi Isolated from Maize (Zea mays L.) Grains and Production of Associated Enzyme Activities. Int. J. Mol. Sci. 2015, 7, 15328-15346. [CrossRef]

2. Xing, H.Q.; Ma, J.C.; Xu, B.L.; Zhang, S.W.; Wang, J.; Cao, L.; Yang, X.M. Mycobiota of maize seeds revealed by rDNA-ITS sequence analysis of samples with varying storage times. MicrobiologyOpen 2018, 7, e00609. [CrossRef] [PubMed]

3. Wang, L.; Liu, B.; Jin, J.; Ma, L.; Dai, X.; Pan, L.; Liu, Y.; Zhao, Y.; Xing, F. The Complex Essential Oils Highly Control the Toxigenic Fungal Microbiome and Major Mycotoxins During Storage of Maize. Front. Microbiol. 2019, 10, 1643. [CrossRef]

4. Gromadzka, K.; Błaszczyk, L.; Chełkowski, J.; Waśkiewicz, A. Occurrence of Mycotoxigenic Fusarium Species and Competitive Fungi on Preharvest Maize Ear Rot in Poland. Toxins 2019, 11, 224. [CrossRef]

5. Shoresh, M.; Harman, G.E. The molecular basis of shoot responses of maize 517 seedlings to Trichoderma harzianum T22 inoculation of the root: A proteomic approach. Plant Physiol. 2008, 147, 2147-2163. [CrossRef]

6. Wicklow, D.T.; Roth, S.; Deyrup, S.T.; Gloer, J.B. A protective endophyte of maize: Acremonium zeae antibiotics inhibitory to Aspergillus flavus and Fusarium verticillioides. Mycol. Res. 2005, 109, 610-618. [CrossRef]

7. Wicklow, D.T.; Poling, S.M. Antimicrobial activity of pyrrocidines from Acremonium zeae against endophytes and pathogens of maize. Phytopathology 2009, 99, 109-115. [CrossRef]

8. Summerbell, R.C.; Gueidan, C.; Schreors, H.J.; de Hoog, G.S.; Staring, M.; Arocha Rosete, Y.; Guarro, J.; Scott, J.A. Acremonium phylogenetic overview and revision of Gliomastix, Sarocladium, and Trichothecium. Stud. Mycol. 2011, 68, 139-162. [CrossRef]

9. Ownley, B.H.; Gwinn, K.D.; Vega, F.E. Endophytic fungal entomopathogens with activity against plant pathogens: Ecology and evolution. BioControl 2010, 55, 113-128. [CrossRef]

10. Dolatabad, H.K.; Javan-Nikkhah, M.; Shier, W.T. Evaluation of antifungal, phosphate solubilisation, and siderophore and chitinase release activities of endophytic fungi from Pistacia vera. Mycol. Prog. 2017, 16, 777-790. [CrossRef]

11. Nirenberg, H. Untersuchungen über Die Morphologische und Biologische Differenzierung in der Fusarium-Sektion Liseola; Kommissionsverlag Paul Parey: Berlin, Germany, 1976.

12. Shinde, S.V.; Patel, K.G.; Purohit, M.S.; Pandya, J.R.; Sabalpara, A.N. Lecanicillium lecanii (Zimm) Zare and Gams an important biocontrol agent for the management of insect pests-A Review. Agric. Rev. 2010, 31, 235-252.

13. Vilgalys, R.; Hester, M. Rapid genetic identification and mapping of enzymatically amplified ribosomal DNA from several Cryptococcus species. J. Bacteriol. 1990, 172, 4238-4246. [CrossRef] [PubMed]

14. Rehner, S.A.; Samuels, G.J. Molecular systematics of the Hypocreales: A teleomorph gene phylogeny and the status of their anamorphs. Can. J. Bot. 1995, 73, 816-823. [CrossRef] 
15. Carbone, I.; Kohn, L. A method for designing primer sets for speciation studies in filamentous ascomycetes. Mycologia 1999, 1,553-556. [CrossRef]

16. National Centre for Biotechnology Information. Available online: http://www.ncbi.nlm.nih.gov (accessed on 12 January 2021).

17. Jestoi, M.; Rokka, M.; Yli-Mattila, T.; Parikka, P.; Rizzo, A.; Peltonen, K. Presence and concentrations of the Fusarium-related mycotoxins beauvericin, enniatins and moniliformin in finish grain samples. Food Addit. Contam. 2004, 21, 794-802. [CrossRef]

18. Kanaoka, M.; Isogai, A.; Murakoshi, S.; Ichinoe, M.; Suzuki, A.; Tamura, S. Bassianolide, a new insecticidal cyclodepsipeptide from Beauveria bassiana and Verticillium lecanii. Agric. Biol. Chem. 1978, 42, 629-635. [CrossRef]

19. Soman, A.G.; Gloer, J.B.; Angawi, R.F.; Wicklow, D.T.; Dowd, P.F. Vertilecanins: New phenopicolinic acid analogues from Verticillium lecanii. J. Nat. Prod. 2001, 64, 189-192. [CrossRef]

20. He, H.; Yang, H.Y.; Bigelis, R.; Solum, E.H.; Greenstein, M.; Carter, G.T. Pyrrocidines A and B, new antibiotics produced by a filamentous fungus. Tetrahedron Lett. 2002, 43, 1633-1636. [CrossRef]

21. Reddy, C.S.; Holbert, J.R. The black bundle disease of corn. J. Agric. Res. 1924, 27, 177-206.

22. Tagne, A.; Neergaard, E.; Hansen, H. Studies of Host-pathogen Interaction between Maize and Acremonium strictum From Cameroon. Eur. J. Plant Pathol. 2002, 108, 93-102. [CrossRef]

23. Racedo, J.; Salazar, S.M.; Castagnaro, A.P.; Díaz Ricci, J.C. A strawberry disease caused by Acremonium strictum. Eur J. Plant Pathol. 2013, 137, 649-654. [CrossRef]

24. Potshangbam, M.; Devi, S.I.; Sahoo, D.; Strobel, G.A. Functional Characterization of Endophytic Fungal Community Associated with Oryza sativa L. and Zea mays L. Front. Microbiol. 2017, 8, 325. [CrossRef]

25. Cobo-Díaz, J.F.; Baroncelli, R.; Le Floch, G.; Picot, A. Combined Metabarcoding and Co-occurrence Network Analysis to Profile the Bacterial, Fungal and Fusarium Communities and Their Interactions in Maize Stalks. Front. Microbiol. 2019, 10, 261. [CrossRef]

26. Zare, R.; Gams, W. A revision of Verticillium section Prostrata. IV. The genera Lecanicillium and Simplicillium gen. nov. Nova Hedwig. 2001, 73, 1-50.

27. Kepler, R.M.; Luangsa-Ard, J.J.; Hywel-Jones, N.L.; Quandt, C.A.; Sung, G.H.; Rehner, S.A.; Aime, M.C.; Henkel, T.W.; Sanjuan, T.; Zare, R.; et al. A phylogenetically-based nomenclature for Cordycipitaceae (Hypocreales). IMA Fungus 2017, 8, 335-353. [CrossRef]

28. Sung, G.-H.; Hywel-Jones, N.L.; Sung, J.-M.; Luangsa-ard, J.J.; Shrestha, B.; Spatafora, J.W. Phylogenetic classification of Cordyceps and the clavicipitaceous fungi. Stud. Mycol. 2007, 57, 5-59. [CrossRef] [PubMed]

29. Goettel, M.S.; Koike, M.; Kim, J.J.; Aiuchi, D.; Shinya, R.; Brodeur, J. Potential of Lecanicillium spp. for management of insects, nematodes and plant diseases. J. Invertebr. Pathol. 2008, 98, 256-261. [CrossRef] [PubMed]

30. Nicoletti, R.; Becchimanzi, A. Endophytism of Lecanicillium and Akanthomyces. Agriculture 2020, 10, 205. [CrossRef]

31. Sánchez-Márquez, S.; Bills, G.F.; Zabalgogeazcoa, I. Diversity and structure of the fungal endophytic assemblages from two sympatric coastal grasses. Fungal Divers. 2008, 33, 87-100.

32. Sánchez-Márquez, M.; Bills, G.F.; Zabalgogeazcoa, I. The endophytic mycobiota of the grass Dactylis Glomerata. Fungal Divers. 2007, 27, 171-195.

33. Poosakkannu, A.; Nissinen, R.; Kytöviita, M.M. Culturable endophytic microbial communities in the circumpolar grass, Deschampsia flexuosa in a sub-Arctic inland primary succession are habitat and growth stage specific. Environ. Microbiol. Rep. 2015, 7, 111-122. [CrossRef] [PubMed]

34. Molina-Montenegro, M.A.; Oses, R.; Torres-Díaz, C.; Atala, C.; Núñez, M.A.; Armas, C. Fungal endophytes associated with roots of nurse cushion species have positive efects on native and invasive beneficiary plants in an alpine ecosystem. Perspect. Plant Ecol. Evol. Syst. 2015, 17, 218-226. [CrossRef]

35. Giordano, L.; Gonthier, P.; Varese, G.C.; Miserere, L.; Nicolotti, G. Mycobiota inhabiting sapwood of healthy and declining Scots pine (Pinus sylvestris L.) trees in the Alps. Fungal Divers. 2009, 38, 69-83.

36. Behnke-Borowczyk, J.; Kwaśna, H.; Kulawinek, B. Fungi associated with Cyclaneusma needle cast in Scots pine in the west of Poland. For. Pathol. 2019, 49, e12487. [CrossRef]

37. Gurulingappa, P.; Sword, G.A.; Murdoch, G.; McGee, P.A. Colonization of crop plants by fungal entomopathogens and their efects on two insect pests when in planta. Biol. Control 2010, 55, 34-41. [CrossRef]

38. de Souza Vieira, P.D.; de Souza Motta, C.M.; Lima, D.; Torres, J.B.; Quecine, M.C.; Azevedo, J.L.; de Oliveira, N.T. Endophytic fungi associated with transgenic and non-transgenic cotton. Mycology 2011, 2, 91-97. [CrossRef]

39. Dash, C.K.; Bamisile, B.S.; Keppanan, R.; Qasim, M.; Lin, Y.; Islam, S.U.; Hussain, M.; Wang, L. Endophytic entomopathogenic fungi enhance the growth of Phaseolus vulgaris L. (Fabaceae) and negatively affect the development and reproduction of Tetranychus urticae Koch (Acari: Tetranychidae). Microb. Pathog. 2018, 125, 385-392. [CrossRef]

40. González, V.; Tello, M.L. The endophytic mycota associated with Vitis vinifera in central Spain. Fungal Divers. 2011, 47, 29-42. [CrossRef]

41. Gromadzka, K.; Górna, K.; Chełkowski, J.; Waśkiewicz, A. Mycotoxins and related Fusarium species in preharvest maize ear rot in Poland. Plant Soil Environ. 2016, 62, 348-354. [CrossRef]

42. Wicklow, D.T.; Poling, S.M.; Summerbell, R. Occurrence of pyrrocidine and dihydroresorcylide production among Acremonium zeae populations from maize grown in different regions. Can. J. Plant Pathol. 2008, 30, 425-433. [CrossRef]

43. Poling, S.M.; Wicklow, D.T.; Rogers, K.D.; Gloer, J.B. Acremonium zeae, a protective endophyte of maize, produces dihydroresorcylide and 7-hydroxydihydroresorcylides. J. Agric. Food Chem. 2008, 56, 3006-3009. [CrossRef] 